\title{
Lógica y ética trascendental en la concepción de la ley en Francisco Suárez
}

OSCAR YANGALI

Pontifica Universidad Católica del Perú

Resumen: La finalidad del presente trabajo es la de mostrar un estudio sobre la concepción de la ley en Francisco Suárez a la luz de una lógica y ética trascendental propuesta por Ludwig Wittgenstein con el propósito de ofrecer una vinculación entre ambas posturas respecto de la naturaleza y formulación de nuestras leyes y reglas. Primero, examino la teoría suareciana de la intelección y la ciencia. Segundo, examino la teoría wittgensteiniana sobre la lógica y los juegos del lenguaje. Y, por último, desarrollo una comparación entre la consideración de la ley de acuerdo con Suárez y la ética de acuerdo con Wittgenstein como valoraciones trascendentales que sirven de análisis para nuestras prescripciones y acciones.

Palabras clave: Suárez, Wittgenstein, ciencia, ley, trascendental.

Abstract: The aim of the present work is to show a study on the conception of the law in Francisco Suárez in the light of a transcendental logic and ethics proposed by Ludwig Wittgenstein with the purpose of offering a link between both positions regarding the nature and formulation of our laws and rules. First, I examine the Suarezian theory of intellection and science. Second, I examine the Wittgensteinian theory of logic and language games. Finally, I develop a comparison between the consideration of the law according to Suárez and ethics according to Wittgenstein as transcendental assessments that serve as analyses for our prescriptions and actions.

Keywords: Suárez, Wittgenstein, science, law, transcendental. 


\section{§ 1. Introducción}

¿Es posible establecer un nexo entre el pensamiento de Suárez en torno a la ley y el desarrollo de Wittgenstein acerca de una ética trascendental? ¿Cómo tendría que exponerse semejante comparación entre ambos autores de manera que su distancia y respectivos paradigmas no sean un impedimento? Para lograr este propósito considero que la conexión tiene que ser establecida bajo la lógica o metodología del conocimiento de ambos, de modo que sea factible comprender la noción de ley suareciana a la luz de los planteamientos de Wittgenstein con el fin de resaltar qué aspecto trascendental cobra la teoría jurídica expuesta por Suárez. La importancia de este examen consiste, entonces, en desarrollar un comentario esclareciendo la naturaleza de la ley y de la ética en ambos autores donde el aspecto común sea el de tratarlas como juegos del lenguaje.

\section{§ 2. Suárez y la forma de la intelección}

Suárez llama la atención sobre nuestro conocimiento con una concepción de ciencia que no otorga conocimiento directo de los universales. Esto, porque no tenemos experiencia directa de alguno de ellos sino tan sólo de entes singulares, dejando a los universales como producto indirecto de nuestra mente en virtud de semejanzas. De manera que, al no preexistir universal alguno respecto del ejercicio de nuestro intelecto, hay que decir que nuestro conocimiento universal encuentra su lugar en nuestro concepto y no in re.

El autor desarrolla esta tesis sobre la base de la distinción entre concepto formal y objetivo que hereda de la escolástica en las Disputaciones Metafísicas'. $^{\prime}$ Y es que según Suárez nosotros conocemos las cosas y desarrollamos nuestra ciencia a partir de una intelección que se compone de ambos momentos. Como señala Suárez: "Se llama concepto formal al acto mismo o, lo que es igual, al verbo con que el entendimiento concibe una cosa $\circ$ una razón común. Se le da el nombre de concepto, porque viene a ser como una

I Para el presente estudio utilizo la siguiente edición y traducción de Sergio Rábade Romeo, Salvador Caballero Sánchez y Antonio Puigcerver Zanón del960. 
concepción de nuestra mente; y se le llama formal, bien porque es la última forma de la mente, bien porque representa formalmente al entendimiento la cosa conocida, bien porque, en realidad, es el término formal e intrínseco de la concepción mental, consistiendo, por así decirlo, en esto su diferencia del concepto objetivo" (1960, 36I).

El concepto formal según Suárez se entiende como el acto de entender, una representación meramente formal del conocimiento directo de la cosa. Así, continúa Suárez: "Llamamos concepto objetivo a la cosa o razón que, propia e inmediatamente, se conoce o representa por medio del concepto formal; por ejemplo: cuando concebimos un hombre, el acto que realizamos para concebirlo en la mente se llama concepto formal, en cambio, el hombre conocido y representado en dicho acto se llama concepto objetivo" (1960, 36I).

Por concepto objetivo Suárez explica que se trata de lo entendido o representado mediante el concepto formal. De esta manera lo representado en el concepto objetivo es reflejo del concepto formal. Para Suárez todo lo que podemos entender es fruto de este doble momento conceptual. Estos conceptos, formal y objetivo, son los que configuran nuestro modo de conocer, pues son el acto de entender y lo entendido, "por eso, con toda razón se le llama objetivo [al concepto objetivo], porque no se trata de un concepto que sea, en cuanto forma, término intrínseco de la concepción, sino en cuanto objeto y materia a que se aplica la concepción formal" (1960, 36I). Por ello, Suárez menciona que algunos llaman al concepto objetivo también intención entendida o razón objetiva. De manera que es imposible comprender el modo de conocimiento sino partiendo de esta configuración intencional de nuestro intelecto.

Y es que, para Suárez, la unidad del concepto objetivo consiste en una unidad formal que no es otra cosa que la conveniencia o semejanza (1960, 384), por lo que una razón esencial como concepto objetivo no es algo real en las cosas sino sólo algo obtenido del concepto formal de los singulares². Por ello: "el concepto formal es siempre algo singular e individual" (1960, 36I). De modo que, de acuerdo con esta metodología, no podemos asumir esencias reales

2 Así, Suárez afirmará el conocimiento directo del singular, algo propio de su filosofía; $y$, por tanto, el conocimiento del universal es tan sólo indirecto $(1960,762)$. 
colocadas uniformemente en las cosas sino tan sólo semejanzas que hallamos entre las mismas. Ahora bien, a esto hay que añadir las tesis de Suárez acerca de los universales, pues hay que decir que, como consecuencia del rechazo de una realidad del universal in re, la concepción suareciana de dicho universal encontrará su fundamento fuera de las cosas en un plano estrictamente conceptual. Como señala Iturrioz: "Esta confusión abstractiva viene a 'despersonalizar' a los objetos, reteniendo en ellos lo que es menos de ellos y más de otros a la vez" $(1949,253)$. Las cosas extra mentales serán representadas por nuestros conceptos formales de los singulares para reunirlos objetivamente en un universal.

Así, a relación entre los entes singulares y la razón común es de una jerarquía donde el individuo se encuentra sometido a la especie oponiéndose a ella de un modo cuasi privativo, así como se opone la unidad a la multitud. $Y$ es que concebimos la razón común como aquello que se encuentra en muchos mientras llamamos individual al ente singular. De modo que la razón común se debería comunicar hacia los entes individuales por pertenecer estos a la misma especie, mientras que un ente concreto no podría ser susceptible de ello por ser precisamente una entidad numéricamente una-(Suárez 1960, 564). Así pues, todas las cosas que son entes actuales o que existen son singulares $(1960,566)$. Por ello, Suárez sostiene que el fundamento de un ente singular radica en su propia individualidad, ya que la naturaleza contraída formalmente de dos o más entes singulares es precisamente sólo una contracción formal pero no real. Es decir, que no existe una naturaleza real que fuera común y a su vez individual porque ello encerraría una contradicción.

Por ejemplo, si en Pedroy Pablo ocurriera una doble composición de naturaleza universal y de su propia individualidad tendríamos el problema de explicar cómo no sólo son dos individuos distintos compartiendo una misma naturaleza común sino que existen separados uno del otro $(1960,579)$. Por lo que hablar de una naturaleza común en ambos resulta imposible debido a que serían dos naturalezas reales pero distintas o diferenciadas individualmente. Así, "esta identidad formal, en cuanto puede existir en la realidad, es sólo una cierta semejanza que supone la distinción real y, por consiguiente, la individuación de aquellas cosas que se dicen semejantes" $(1960,579)$. De este modo, la unidad de la especie sólo es producto de la razón, no una realidad compartida pues ello sería, para Suárez, un contrasentido. Cada ente singular es su mismo 
principio de individuación o negación de la especie común. Pero ya que la especie común o universal no es una realidad que exista en él aparte de su realidad individual, la diferencia de naturaleza común y la del ente singular es sólo una distinción conceptual o de razón, pero no es real (1960, 644-645). EI fundamento o principio de individuación que contrae la especie o naturaleza común hacia el ente individual es el mismo ente individual en cuanto tal. No es ni su forma ni su materia sino el ente como tal integralmente $(1960,659)$.

¿Por qué es importante señalar en este presente estudio que la unidad universal no es algo real para Suárez? Pues, más allá de que se señale que sólo las cosas singulares son existentes o reales, hay que decir que, para Suárez, el universal es un producto de nuestro conocimiento. El problema no reside en sostener que nuestro modo de conocer se base en universales sino en creer que estos fueran naturalezas reales comunes residentes en las cosas. De manera que, para Suárez, es necesario postular que "la unidad de la naturaleza universal en cuanto es universal no es real ni se da en las cosas tal como existen en la realidad misma y anteceden [las cosas] a toda operación del entendimiento" $(1960,719)$. Es decir, que los universales deben su unidad sólo a consecuencia de nuestra razón: “(...) en la realidad no hay nada verdaderamente uno y realmente indiviso en ésta y aquella naturaleza humana, sino que en ésta hay sólo algo a lo que a su vez responde algo semejante en la otra naturaleza; esto, empero, no es unidad real, sino semejanza" (1960, 719-720).

Podría pensarse que todas las cosas semejantes entre sí deben guardar un principio real y común en todas ellas para poderse definir de la misma especie. No obstante, esa unidad universal no es real como lo son las cosas, sino que es una configuración que producimos a partir de las semejanzas que entre ellas encontramos.

Así, para Suárez, hablar de la esencia es hablar en realidad de la semejanza que se evidencia. No existe alguna unidad formal residente en las cosas que sea la misma en todas idénticamente, de manera que sólo hay que decir que la unidad del concepto objetivo es producto de la eficacia del intelecto en cuanto puede abstraer un concepto objetivo común (1960, 732-733). De esta manera, “(...) tampoco hay en la naturaleza común, considerada en sí misma, aptitud alguna para comunicarse a muchos, distinta de la no repugnancia que hay en los individuos para tener otros semejantes" (1960, 746). Esta comunicación 
de una naturaleza común, sobre la base de una no repugnancia o semejanza, es realizada por el intelecto mediante nociones universales. Por lo que si el hecho de que la naturaleza pueda multiplicarse en muchos es entendido como una capacidad superior de una naturaleza común que se concibe como comunicándose a muchos será una labor de la razón y un modo nuestro de concebir, no de otro modo. Así: "Este es el sentido en que se afirma que la ciencia se ocupa de los universales y no de los singulares, no porque se ocupe de los nombres comunes, sino porque se ocupa de los conceptos objetivos comunes, que aunque no se distinguen de los singulares en la realidad, se distinguen, sin embargo, por razón, (...)” (1960, 750).

La ciencia, aquella que se ocupa de los conceptos objetivos que no son sino reflejos de los conceptos formales, distingue las cosas singulares sólo por razón mediante los universales. Agrega Suárez que por eso los nominalistas no se han expresado igual solamente porque no explicaron bien cómo se concibe un concepto objetivo aferrándose únicamente a los términos singulares, aunque no se diferencian mucho de su modo de concebir las cosas.

Según Suárez somos capaces de examinar el fin del intelecto mismo en su ejercicio de intelección de los universales pues consiste precisamente en abstraer grados y razones formales (1960, 770). Así, Suárez agregará que el intelecto "no sólo procura conocer las naturalezas de las cosas, sino también las denominaciones o relaciones que parecen tener en cuanto se ofrecen al entendimiento mismo, y éste es el fin por el que elabora los universales y concibe sus relaciones" $(1960,770)$. $Y$ es que precisamente los universales son elaborados mediante relaciones entre las cosas y conforme al modo en que se presentan.

Como conclusión provisional del presente capítulo, he presentado en Suárez una metodología que encuentra su fundamento en la intención del concepto formal hacia un concepto objetivo. Luego, el conocimiento es posible gracias a la capacidad de nuestra intelección de poder formalizar una razón común o universal en virtud de las semejanzas que encontramos entre las cosas. Por lo tanto, nuestros conceptos no son representaciones tal cual de las cosas singulares, sino configuraciones en nuestros conceptos. 


\section{$\S 3$. Wittgenstein y la lógica del conocimiento}

Wittgenstein plantea que nuestra comprensión de las cosas y del mundo se encuentra configurada por nuestro lenguaje; no obstante, no sólo hablará de hechos como de estados de cosas simples sino que los mismos se encontrarán estructurados bajo diversos usos del lenguaje. De modo que, al tratar la forma lógica no como una estructura fija sino como una estructura funcional del uso que le damos en nuestro mundo, hay que decir que nuestro conocimiento se encuentra configurado en diversos juegos del lenguaje.

Wittgenstein en el Tractatus logico-philosophicus ${ }^{3}$ desarrolla una serie de pensamientos en torno al lenguaje y al mundo. Señala: “(I) El mundo es todo lo que es el caso. / (I.I) El mundo es la totalidad de los hechos, no de las cosas. / (I.II) El mundo viene determinado por los hechos, y por ser éstos todos los hechos. / (I.I2) Porque la totalidad de los hechos determina lo que es el caso y también todo cuanto no es el caso. / (I.I3) Los hechos en el espacio lógico son el mundo. / (I.2I) Algo puede ser el caso o no ser el caso, y todo lo demás permanecer igual. / (2) Lo que es el caso, el hecho, es el darse efectivo de estados de cosas. / (2.0I) El estado de cosas es una conexión de objetos (cosas). / (2.0II) Poder ser parte integrante de un estado de cosas es esencial a la cosa" (2009, 49-50).

Wittgenstein escribe en estas líneas que nuestro mundo no consiste sino en la totalidad de lo que consideramos de los hechos y no de las cosas. Es decir, concebimos al mundo no como un conjunto de cosas sino como un conjunto de hechos. Ahora bien, ¿qué es un hecho y en qué se diferencia de las cosas? Nos dice Wittgenstein que un hecho es básicamente un estado de cosas, esto es, una relación o conexión de cosas entre sí, por lo que un hecho efectivamente conforma no una cosa sino un estado o espacio lógico por medio del cual somos capaces de comprender el mundo como una totalidad. Así, es parte de la esencia de las cosas el pertenecer a dicho estado o conexión.

3 En este estudio utilizo la traducción autorizada de la edición publicada por Routledge, sello del grupo Taylor \& Francis,, 2009. En adelante, el título será abreviado como TLP y se mantendrá la enumeración del Tractatus cada vez que se aluda a un enunciado. 
A esto, cabe señalar que Wittgenstein añade a su teoría una serie de reflexiones acerca del lenguaje y nuestro modo de conocer. Este estado de cosas es configurado a modo de eslabones de una cadena (TLP 2.03), por ello observamos una interrelación estructurada que resulta en un comportamiento determinado (TLP 2.03I), a la cual intentaremos traducir mediante formas. Pero nuestro concepto de forma se deriva de la posibilidad tomada de dicha estructura (TLP 2.033), por lo que nuestra configuración no es arbitraria en la medida que traduce esta interrelación dada de los objetos.

Ahora bien, Wittgenstein utiliza la noción de figura para señalar el modelo que nos hacemos de la realidad (TLP 2.12), así pues, nos hacemos figuras de los estados de cosas o hechos (TLP 2.I). La figura llega o se enlaza con la realidad (TLP 2.I5II), de manera que hay decir que la figura lógica configura el mundo (TLP 2.19). Así, configuramos la realidad de acuerdo con nuestra capacidad representativa de los hechos. Sólo así la figura es capaz de otorgar sentido a las cosas (TLP 2.22I), ya que la figura configura cualquier cosa que pueda representar mediante su forma (TLP 2.I7I). Por ello, nuestro pensamiento es una figura lógica de los hechos (TLP 3) y " "Un estado de cosas es pensable» quiere decir: Podemos hacernos una figura de él” (TLP 3.00I). Por este motivo es inevitable hablar acerca del sentido de nuestras figuraciones mediante las proposiciones que usamos para representar el mundo, pues la proposición es la proyección que realizamos para configurar el mundo. Debido a esto, hay que decir que nuestras proposiciones poseen sentido en la medida que se proyectan al mundo (TLP 3.II), es decir, que la proposición es la condición de posibilidad de todo aquello que configuramos (TLP 3.13). No existe otra posibilidad que la proposición para expresar el sentido de un estado de cosas, de manera que solamente en la trama de una proposición proferimos significados (TLP 3.3). Así, para Wittgenstein, las proposiciones no son sino los signos que usamos para comprender nuestra realidad y vincularnos con ella, o también podríamos decir que las proposiciones son inherentes al mundo en cuanto que sólo somos capaces de pensarlo lógicamente como proposiciones mediante signos y coordenadas lógicas (TLP 3.4I), esto es, que nuestro espacio lógico y el mundo no son sino la misma realidad, la totalidad de los hechos.

Es de aquí de donde se infiere que nuestro lenguaje no sólo es concomitante al mundo, sino que es imposible concebirlo obedeciendo otra lógica. Así, la totalidad de las proposiciones es el lenguaje (TLP 4.00I), es decir, nuestro 
lenguaje son proposiciones con sentido (TLP 4). La proposición es una figura del mundo, ya que por medio de ella representamos lo que pensamos (TLP 4.01). Ahora, Wittgenstein asegura que la proposición no puede representar a la forma lógica, ya que ésta se refleja más bien a través de ella porque la proposición muestra la forma lógica de la realidad (TLP 4.I2I). Y es que al ser la proposición la condición de posibilidad del sentido donde referimos hechos, no puede ser enunciada del mismo modo en que se enuncian los hechos por su forma lógica.

Por el contrario, Wittgenstein enuncia: "Lo que puede ser mostrado, no puede ser dicho" (TLP 4.I2I2), de manera que la forma lógica no se dice, sino que se muestra en la proposición. En el Tractatus, este mostrarse es entendido como algo que se da a partir de una estructura o "relación interna" que la proposición comprende de las cosas (TLP 4.I22), y es como una "propiedad interna" de un posible estado de cosas que no es representado por una proposición sino más bien que viene en la misma (TLP 4.I24). Y es que este modo de hablar de propiedades formales nos conduce a hablar de conceptos formales (TLP 4.126), los cuales va a usar Wittgenstein para señalar aquellos conceptos que no refieren sino a este darse efectivo de la proposición. Como afirma Wittgenstein: "Los conceptos formales, en efecto, no pueden ser representados, como los conceptos propios, por una función. / Porque sus rasgos distintivos, las propiedades formales, no se expresan mediante funciones. / La expresión del concepto formal es, pues, un rasgo de ciertos símbolos. / El signo de los rasgos distintivos de un concepto formal es, pues, un rasgo característico de todos los símbolos cuyos significados caen bajo el concepto. / Así pues, la expresión del concepto formal es una variable proposicional en la que sólo este rasgo característico es constante" (2009, 76-77).

El concepto formal para Wittgenstein consiste no en una representación o función como cualquier otro tipo de conceptos, pues para expresar las propiedades formales es necesario referirse al rasgo característico constante de todo símbolo. Yesto sólo puede recogerse a modo de la variable proposicional. Por tanto, todo concepto formal no es entendido sino como tal.

Podemos entender mejor, entonces, que "La forma general de la proposición es una variable” (TLP 4.53), pues dicha forma intenta traducir el modo en cómo se comportan las cosas (TLP 4.5). Wittgenstein señala que la forma 
general de la proposición es su misma esencia (TLP 5.47I), de manera que la descripción de una proposición debe coincidir con su esencia y con el mundo (TLP 5.47II). Esto tiene que ver, por supuesto, con que la lógica sea por ello a priori por ser condición de posibilidad, pues nada ilógico podría ser pensado (TLP 5.473I), y que el sentido posibilita el significado de cualquier hecho (TLP 5.4733). Por lo tanto, "Los límites de mi lenguaje significan los límites de mi mundo" (TLP 5.6), pues sólo aquello que podemos comprender mediante la lógica es lo que podemos configurar para el mundo. Sólo entendemos lo que significa algo dentro de los límites de nuestro lenguaje. Por ello, y en vista de lo anterior, conviene señalar que: "La tarea más importante de Wittgenstein en el Tractatus consiste en mostrar o elucidar la distinción entre lo que puede decirse y lo que no" (Fann 2003, 5). Así también hay que comprender lo que Wittgenstein entiende por ciencia, pues la totalidad de las proposiciones verdaderas es lo que conforma nuestra ciencia natural (TLP 4.II). Y esto es importante a tomar en cuenta pues quiere reafirmarse una vez más que la ciencia está sujeta a la forma lógica de las proposiciones, es decir, que la condición de la posibilidad de la ciencia en cuanto tal es la forma lógica. Por ello, la lógica es trascendental (TLP 6.13).

Por esta razón para el primer Wittgenstein la veracidad de la ciencia se encuentra en la posibilidad de los estados de cosas. Un hecho es verdadero si nuestra proposición coincide con él. Así, hablamos de proposiciones elementales cuando hablamos de esta correspondencia con el darse efectivo de un estado de cosas (TLP 4.2I). Este tipo de proposiciones no puede contradecirse entre sí debido a su encadenamiento en la realidad (TLP 4.22). Por esta razón, las proposiciones elementales, de ser verdaderas, deben describir un estado de cosas que se da efectivamente (TLP 4.26). ¿Cómo es posible esta correspondencia? Pues para el primer Wittgenstein la figura consiste en que sus elementos se interrelacionan de un modo determinado (TLP 2.14); de manera que, al poder interrelacionarnos con un estado de cosas, sólo sería posible esta interrelación de poder captarse una estructura (TLP 2.15). Por ello la forma de nuestras configuraciones es la posibilidad de esta interrelación (TLP 2.15I) y así, inevitablemente, hallamos que nuestras proposiciones más elementales deben corresponderse con la realidad (TLP 2.I5II).

Consecuentemente, Wittgenstein señala que la posibilidad de verdad de una proposición elemental son las condiciones de verdad de la misma (TLP 4.4I). 
Como Mounce dice: "En el Tractatus, la forma lógica es algo que, por así decir, está en la base de las reglas del lenguaje y garantiza su uso inteligible” (2007, 48). Por ello, para explicar esto nos hemos valido usualmente de los esquemas de valores de verdad también conocidos como las tablas de verdad.

Ahora bien, sabemos que el segundo Wittgenstein en las Investigaciones Filosóficas ${ }^{4}$ rechaza la correspondencia de proposiciones elementales con los hechos pues considera que no hay modo de garantizar que los nombres como tales refieran a estados de cosas simples ${ }^{5}$. Para el primer Wittgenstein, esta garantía se ofrecía por medio de las condiciones de verdad; no obstante, para el segundo Wittgenstein, esta garantía no es posible de ser supuesta en un mismo sentido porque resulta que dichas condiciones de verdad no son sino diversos usos que le damos al lenguaje.

Para el segundo Wittgenstein hablar de proposiciones elementales u objetos simples es problemático. ¿Cómo puedo referirme a que por ejemplo una silla sea un compuesto de partes simples? "«Simple» quiere decir: no compuesto. $Y$ aquí surge luego: ¿compuesto’ en qué sentido? No tiene ningún sentido hablar absolutamente de 'partes constituyentes simples de la silla'" (IF §47). De manera similar operamos con las palabras que poseen un significado que no es sino el mismo uso que refiere (IF $\S I)$. $Y$ es que nosotros de niños aprendemos las palabras por medio de un adiestramiento y no de alguna explicación formal del significado (IF §5). Es decir, el significado de una palabra refiere al uso que hemos aprendido a darle, y no se corresponde con algún supuesto hecho simple o atómico de la realidad. De modo que: "El atomismo comienza a desvanecerse, y el lenguaje, incluso en el nivel elemental, va tomando los rasgos de un organismo" (Van Peursen 1973, 86). Así, a todo este proceso del uso de palabras Wittgenstein lo llama un juego del lenguaje (IF §7), que no será otra cosa que poner de relieve que hablar un lenguaje forma parte de una actividad o una forma de vida (IF §23). No hay algún juego

4 Se usa la traducción castellana de Alfonso García Suárez y Ulises Moulines del año 2010 y se anota el número de cada parágrafo (§). Asimismo, en las próximas referencias parentéticas el título será abreviado como IF.

5 Tengo presente para este estudio que el segundo Wittgenstein puede y debe ser comprendido en continuación del primero, pues como muy bien dijo él mismo de su trabajo en el prólogo del nuevo libro: “(...) éstos [nuevos pensamientos] sólo podían recibir su correcta iluminación con el contraste y en el trasfondo de mi viejo modo de pensar" $(2010,13)$. 
de lenguaje que represente mejor los estados de cosas pues ello supondría volver a postular hechos simples a los que refieran proposiciones elementales de manera correspondiente.

No hay, pues, esencia alguna que atraviese todos los juegos del lenguaje a no ser alguna semejanza: "En vez de indicar algo que sea común a todo lo que llamamos lenguaje, digo que no hay nada en absoluto común a estos fenómenos por lo cual empleamos la misma palabra para todos -sino que están emparentados entre sí de muchas maneras diferentes. $Y$ a causa de este parentesco, 0 de estos parentescos, los llamamos a todos «lenguaje»" (IF §65).

De manera que para el segundo Wittgenstein no hay nada común al lenguaje excepto esta emparentación. Un juego del lenguaje no es mejor que otro porque pueda acercarse mejor a los hechos. Por ello: “(...) si los miras no verás por cierto algo que sea común a todos, sino que verás semejanzas, parentescos y por cierto toda una serie de ellos” (IF §66). La semejanza es la esencia del lenguaje $y$, por esta misma razón, Wittgenstein rechaza a los nominalistas, pues se limitan a interpretar los términos como nombres pero no examinan la conformidad de empleo o uso de los mismos (IF §383).

Así, debo concluir provisionalmente que la metodología de Wittgenstein concibe al conocimiento como configuración o conceptualización formal que se reproduce mediante juegos del lenguaje a partir de semejanzas. No podemos hablar de alguna especie de traducción formal correspondiente para hechos atómicos puesto que: “(...) si se concibe una exposición como 'Ahora lo entiendo' a la manera de informe (o descripción) de un determinado acto de intelección, hay que aceptar que tal informe no informa, es decir, no puede ser informe (o descripción) de algo" (Hartnack 1972, 132). Sólo nos referimos acerca de conceptos que obtenemos a partir de estas semejanzas como usos comunes según nuestro empleo de las palabras.

\section{§ 4. En torno a la ley y a una ética trascendental}

Hasta aquí, lo que vemos en Suárez como en Wittgenstein se resume en los siguientes puntos. Primero, observo que en la metodología de Suárez se exige que haya una conceptualización formal respecto de lo singular para configurar 
las cosas en los conceptos objetivos. Esto deviene en ciencia y en naturaleza común que no es sino comunicada gracias a las semejanzas. Segundo, observo también que en Wittgenstein existe correlación respecto de la forma lógica de la proposición y los hechos que son configurados. Esto es lo que conforma la ciencia natural; no obstante, hay que señalar que la forma lógica finalmente es asumida por el segundo Wittgenstein como el uso de las palabras en los juegos del lenguaje los cuales guardan una relación de semejanza. De manera que, al tratar ambos autores en sus respectivas metodologías, vemos que para ambos nuestra aproximación hacia las cosas se encuentra condicionada por nuestra forma verbal o lenguaje y la comunicación es posibilitada mediante lo semejante. Entonces, es posible postular que en ambos autores notamos una metodología del conocimiento que puede ser asociada. Esto nos será útil también para sus concepciones morales.

Ante todo, ¿cuál es la explicación que nos brinda Suárez sobre la ley? ¿Qué tipos de leyes existen? Cabe señalar que para Suárez, bajo la herencia escolástica, la ley puede ser entendida ya sea como eterna, o natural, o divina, entre otras denominaciones o diversos tipos. Ahora, para la finalidad del presente trabajo es necesario explicar la relación de los primeros dos tipos, a saber, la ley eterna ${ }^{6}$ y la ley natural ${ }^{7}$, pues incluso hoy se apela a ellas con el fin de justificar lo que es conforme o no a la moral. Sostengo que examinar el vínculo entre estas leyes a la luz del pensamiento de Wittgenstein nos puede mostrar una interpretación menos rígida acerca de esta concepción escolástica de ley.

Primero, hay que decir conforme al Tratado de las leyes y de Dios legislador ${ }^{8}$ que los actos del intelecto y voluntad divina no caen bajo ley eterna alguna en cuanto indiquen relación a Dios mismo y a la creación de criaturas futuras (Suárez 1967, 103). Dios no se encuentra sujeto a ningún modelo o ley pues tendría una libertad limitada para crear las cosas al existir un algo previo que lo restringa en su omnipotencia. Por este motivo, respecto de la voluntad

6 Cuando se habla de ley eterna en la escolástica debe entenderse la ley que compete a Dios mismo con anterioridad a la creación del mundo, y que por ello se le denomina "eterna". $7 \quad$ La ley natural es la ley en cuanto ordena conforme a la naturaleza una vez realizada la creación, pues a partir de ahí se debe corresponder con un orden "natural" que podemos descubrir.

8 En este estudio utilizo la versión española de José Ramón Eguillor Muniozguren, vol. I, 1967. 
divina lo que concebimos como la ley eterna no es ley con propiedad, pues sólo la llamamos ley con relación a nuestra concepción. Así, la ley es ley sólo en relación con el gobierno de lo creado, no con relación a Dios mismo (Suárez 1967, 105). La ley eterna no consiste en un acto del intelecto divino precedente a la libertad de Dios, pues ese acto no sería acto libre al estar sujeto ya a un modelo, como sí lo serán los dictámenes de la ley natural los cuales sí proceden del intelecto de Dios posteriores a la creación (Suárez 1967, 108). De manera que "la ley eterna es un decreto libre de la voluntad de Dios por el que determina el orden que deben observar o en general todas las partes del universo con relación al bien general (...) ○ en particular las criaturas intelectuales en cuanto a sus operaciones libres" (Suárez 1967, 109), por lo que la ley eterna per se no refleja un orden sub specie aeternitatis. Este orden será posterior en función del mundo creado para regir nuestra libertad. Por eso Suárez afirmó anteriormente que si bien la ley es un acto de la voluntad y del intelecto, lo es bajo diversos aspectos: a saber, es un acto de la voluntad porque mueve y obliga a obrar, y es un acto del intelecto porque dirige a lo bueno por medio del juicio práctico, el cual curiosamente no precede al acto de la voluntad, a pesar de sonar contra intuitivo, pues en realidad dicho juicio práctico obedece a la voluntad o ley escrita en la mente (1967, 29-30).

Así, dice Suárez: "Hemos explicado el concepto, la universalidad y la necesidad de la ley eterna. Acerca de sus causas no hay por qué decir nada, ya que siendo como es el mismo Dios, no tienen ninguna causa; a lo más puede tener una razón, a la manera como la voluntad divina es la razón principal de la ley divina tal como está en Dios desde la eternidad, o a la manera como puede decirse que la sabiduría divina es la razón de su justísima voluntad, en la cual -según hemos explicado- está la eficacia de esta ley” (Suárez 1967, II2). No hay, pues, otra causa de la ley eterna sino la divina voluntad, relegando al entendimiento de Dios como posterior a la creación. Sólo es posible que Dios comprenda un modelo de ley siendo este creado, y no uno anterior al que él estuviera sometido.

De otra parte, Wittgenstein en el Tractatus piensa que la creación del mundo por parte de un Dios tendría que ver con la manifestación de las leyes lógicas, pues Dios se vería sujeto a no poder transgredir los principios lógicos (TLP 3.03I). Y que por eso, si un dios crea un mundo donde determinadas proposiciones fueran verdaderas, estaría creando un mundo donde todo lo 
que siga de ellas tendría que ser verdadero (TLP 5.123). Ahora, lo importante aquí es que el sentido del mundo no puede pertenecer al mundo mismo, pues el sentido está vinculado esencialmente a la proposición, la cual no dice sino muestra la forma lógica. De esta forma, para Wittgenstein, lo místico no consiste en cómo sea el mundo sino en que este sea (TLP 6.44), pues lo místico no se condice con otra cosa que lo inexpresable, aquello que no se puede decir sino que simplemente se muestra (TLP 6.522). Por ello Wittgenstein afirmaba: "Cómo sea el mundo es de todo punto indiferente para lo más alto. Dios no se manifiesta en el mundo" (TLP 6.432), es decir, Dios no se dice justamente por no ser un hecho del mundo, simplemente se muestra como sentido. Existe una interrelación entre lo que se dice y se muestra, pero no son lo mismo.

Ahora, a partir de lo dicho por Suárez en cuanto la ley eterna es la ley de Dios pero sólo respecto de nosotros, hay que señalar un parecido en cuanto afirma que no la podemos conocer directamente sino por medio de las otras leyes, ya que los hombres en esta vida no pueden conocer la voluntad divina sino por ciertos efectos, y sólo así las leyes temporales manifiestan la fuente de la que dimanan (1967, I14). Por eso afirma Suárez: "Como razón general de ello puede darse que la ley eterna es ley por esencia y todas las otras lo son por participación; luego es preciso que toda ley sea efecto de la ley eterna" (1967, II3). De modo que la participación del hombre en la ley de Dios reside principalmente en obedecer y comunicar su voluntad, no en comprender un misterio. Algo similar a Wittgenstein en cuanto este piensa que la proposición no dice, sino que muestra su sentido, o lo místico; por lo que el sentido del mundo y del valor en cuanto tal sólo puede residir fuera del suceder por suceder del mundo, pues es lo casual (TLP 6.4I). Así, se podría decir que: “la ética no resulta expresable. La ética es trascendental. (Ética y estética son una y la misma cosa)" (TLP 6.42I). Donde lo ético tampoco puede decirse en proposiciones sino que se muestra, es valor y mística.

Sin embargo, según Suárez, la razón natural es capaz de formarse un concepto de ley de acuerdo con principios formales que repugnan la contradicción. Este concepto de ley lo conocemos precisamente como ley natural. Esta ley se denomina natural pues nos brinda un código de honestidad o fealdad conforme con la naturaleza racional para mandar o prohibir (1967, II6). Así, en cuanto se condice la razón natural con la naturaleza común de las cosas resulta nuestra conceptualización formal de la ley natural, la que no puede 
ser contradictoria. Suárez señala: "Por consiguiente, este dictamen es ley natural y por razón de él se dice que el hombre que se guía por él es ley para sí mismo, porque tiene la ley escrita en sí misma mediante el dictamen de la razón natural" (1967, II8). Esto quiere decir que la manera en que la ley natural reside en nosotros es por medio de nuestra capacidad racional y conceptos formales, encontrando cierto fundamento en la naturaleza común de las cosas. No obstante, Suárez también indica que la ley natural "está en el hombre porque no está en Dios, siendo como es temporal y creada; y no está fuera de los hombres, porque no está escrita en tablas sino en el corazón (...)" (1967, II8), por lo que hay que decir consecuentemente que los hombres la poseemos por naturaleza en cuanto reside en nuestra capacidad racional, la cual se condice con nuestro corazón.

En este punto es prudente citar las palabras de Wittgenstein en su Conferencia sobre ética: "En lugar de decir que la ética es la investigación sobre lo bueno, podría haber dicho que la ética es la investigación sobre lo valioso o lo que realmente importa, o podría haber dicho que la ética es la investigación acerca del significado de la vida, o de aquello que hace que la vida merezca vivirse, o de la manera correcta de vivir" (1990, 34-35).

La ética no es sino el discurso de lo valioso, pues lo auténticamente ético se muestra y no se enuncia por medio de proposiciones sobre lo bueno. El significado de la vida no se reduce a ello, sino que es vivir conforme a lo valioso. Añade: "La ética, de ser algo, es sobrenatural y nuestras palabras sólo expresan hechos, del mismo modo que una taza de té sólo podrá contener el volumen de agua propio de una taza de té, por más que se vierta un litro en ella" (Wittgenstein 1990, 37). Por este motivo, la ética es trascendental.

La ética es entendida como trascendental por Wittgenstein pues no reside sino en el valor, al punto que afirma que por ello la ética es estética. Esto lo afirma puesto que, más allá de alguna actitud proposicional, poseemos la capacidad de sentir y valorar. Con lo que podemos afirmar que según Wittgenstein nuestra capacidad lógica se condice con nuestra capacidad estética por tener el mismo fundamento trascendental tanto nuestras formas lógicas como nuestras valoraciones. La ética trascendental puede ser comparada con la ley eterna concebida por Suárez en la medida que esta también refiere a un ámbito trascendente al mundo, razón por la cual se caracteriza por ser 
como una impresión de nuestras estimaciones. Dice Suárez: "es propiamente preceptiva respecto de los hombres (...), pues en cuanto que alcanza a las criaturas inferiores, es cosa clara que no impone obligación propiamente dicha sino instinto o ímpetu que de una manera natural determina a algo" (1967, II2), de manera que la ley eterna no hace sino residir a modo de una estimativa natural.

Es en este sentido que la ley natural será la misma para todos, pues dicha ley no es una propiedad de alguna esencia particular de los individuos sino de la naturaleza específica o formal que es la misma como capacidad para todos. Por lo que somos capaces de derivar las conclusiones que conformarán nuestra denominada ley natural $(1967,134)$. Ya Suárez afirma que “(...) todos los preceptos que se ordenan a un fin de la misma clase, parecen formar un solo derecho y una sola ley" $(1967$, II 2$)$. Ahora, hay que entender esto respecto de lo que podemos comprender mediante nuestros conceptos formales y objetivos, es decir, que tenemos la facultad de conformar y comunicar leyes gracias a cierta naturaleza común o semejanza por medio de nuestra razón natural.

Al respecto dice Baciero: “(...) la recta razón desempeña en la conciencia del hombre el papel de «signo» de la voluntad divina, la única que propiamente ordena o prohíbe las acciones" (2007, II2). Por este motivo, hay que reconocer también que esta razón o luz natural no es algo que opere todo el tiempo sino principalmente para una conservación de la ley natural en nuestros corazones (1967, I19). Esto puede ser comparado con el segundo Wittgenstein, en tanto que no puede objetarse que por rechazar la posibilidad de hechos atómicos al no encerrar estos forma lógica alguna sino tan sólo referir al uso del lenguaje, se estuviera rechazando también el ámbito de lo trascendental o de lo místico. Así, es prudente señalar que esta tesis no se modifica en lo fundamental. Si bien Wittgenstein reconoce que la figura no será sino la condición que posibilita el uso con sentido de un lenguaje (IF §§II4-II6), hay que admitir no obstante que siguen existiendo "límites del lenguaje” en general (IF §II9). De ahí que no hay hechos atómicos, sino que lo único de facto es que establecemos reglas, juegos de lenguaje, de los que se derivan nuestros significados, nuestro "estado civil de la contradicción” (IF §I25). Es de este uso del lenguaje que derivamos nuestras reglas, es decir, formamos una gramática a modo de técnica la cual se traducirá en costumbres, usos e instituciones (IF §I99). Y lo que realizamos es en todo caso una comparación no de objetos sino de juegos de lenguaje 
en virtud de los criterios de semejanza y desemejanza (IF §I3I). Señala por eso Pole: "La naturaleza humana viene reflejada en la gramática humana, en nuestras prácticas lingüísticas fundamentales. Así pues, los seres humanos adoptan naturalmente prácticas lingüísticas divergentes (...) y tratan naturalmente de asimilarlas" (1966, 146). No hay, entonces, alguna esencia idéntica en nuestros discursos sino cierta semejanza para comunicarnos.

En definitiva, he desarrollado dos concepciones morales cuya afinidad metodológica pretendo hacer evidente. Para Suárez la ley que nos gobierna en virtud del orden natural de las cosas, i. e. la ley natural, es comunicada por Dios hacia nosotros directamente de la ley eterna, la cual no se refleja o participa sino de la esencia de la voluntad divina. Sin embargo, el orden natural de las cosas es posterior a la creación, y es posible de ser configurado y comunicado gracias a la naturaleza o semejanza de las cosas. Por otra parte, para Wittgenstein lo que llamamos ética corresponde a un ámbito trascendental, y se encuentra entre nosotros a modo de costumbres e instituciones gracias a los diversos usos que hacemos de los juegos de lenguaje acerca del mundo. No obstante, estos juegos del lenguaje son empleados y reglamentados como tales gracias a la semejanza que hay en ellos. De manera que, al encontrar en ambos autores parecidos en sus concepciones prácticas, resulta filosóficamente interesante señalar esta posible concurrencia con relación a lo jurídico en Suárez a la luz de los análisis de Wittgenstein.

\section{§ 5. Conclusión}

En virtud de lo anterior sostengo que lo dicho por Suárez a la luz de lo dicho por Wittgenstein es posible concebir a la ley natural como un respectivo juego del lenguaje de la ley eterna de Dios. Y afirmo esta interpretación como admisible debido a la comparación de sus respectivas metodologías en torno a lo especulativo y lo práctico.

Para Suárez, en efecto, si bien la ley natural refiere a un orden específico de la naturaleza, este se comunica a partir de nuestra conceptualización formal sin contradicción con las semejanzas encontradas para configurarla en nuestro concepto objetivo, considerando sobre todo nuestra participación en el amor de la voluntad divina, su fundamento último. $Y$ es que la bondad divina y el 
amor son la norma de honestidad de toda ley, que no será sino la ley del amor beatífico que nos espera en la bienaventuranza ya que refleja la naturaleza misma de Dios (1967, 117). De modo que la ley natural auténticamente no reside en nuestras leyes particulares como tales sino en nosotros mismos. Por ello Suárez cita a San Ambrosio: "Esa ley, es decir, la natural, no se escribe sino que nos es innata, ni se percibe con la lectura, sino que brota en cada uno del manantial abundante de la naturaleza" (1967: II8). Es así como debemos legislar con rectitud según Suárez, a saber, con la rectitud que encontramos en el fondo de nuestra razón y de nuestro amor.

Ahora bien, cuando Wittgenstein nos habla de las leyes científicas, concibe que toda investigación de la lógica no es sino una investigación de la legaliformidad concomitante a las mismas (TLP 6.3). Pero cabe recordar que para el Wittgenstein de las Investigaciones la forma lógica o esencia es expresada en la gramática (IF §37I), y por ello derivamos algo como natural conforme a una proposición de esa gramática (IF §372); con lo que también menciona que la gramática es la teología que clasifica a los objetos (IF §373). Sólo así podemos comprender mejor cómo es posible que nuestras configuraciones obedezcan en última instancia a un ámbito místico que se muestra. Por ello, la ética no será sino estética, pues este ámbito místico y trascendental es del que surgen todas nuestras valoraciones, ya que para Wittgenstein el lenguaje es el vehículo de todo nuestro pensamiento (IF §329). Y comparar esto con la teoría jurídica de Suárez es también un punto central del presente estudio, pues no tendría mayor importancia examinar la concepción suareciana de ley a modo de un juego del lenguaje si no es justamente porque Suárez no postula un modelo tan rígido de ley natural como podríamos creer de acuerdo con la tradición escolástica anterior.

Cierto es que el paradigma en el que ubicamos a Suárez normalmente en la historia de la filosofía nos presiona a situarlo entre un cúmulo de autores realistas que sostienen un orden natural de las cosas de manera llana. Pero como he intentado explicar, esta interpretación sobre Suárez sería sesgada pues no describe con una detenida consideración a su pensamiento. Suárez explica a la ley natural también como ejercicio: "Dije antes que la ley natural puede considerarse en acto primero, que es la luz misma intelectual: de ésta consta que es la misma en todos. Además puede darse en acto segundo, es 
decir, en un conocimiento y juicio efectivo, o también en un hábito próximo adquirido por el ejercicio de los actos (...)" (1967, 134).

La ley natural se concibe como acto primero, esto es, como una realidad actual en cuanto es una luz intelectual propia de nuestra naturaleza; no obstante, puede ser concebida también en acto segundo, es decir, como una actividad en virtud de ciertos hábitos para establecer con nuestra capacidad de juicio lo mejor para nosotros.

Y por lo expuesto hasta aquí, hay que decir que no porque Suárez conciba una ley natural como natural la contempla también como libre de errores, aunque, por supuesto, con relación a nuestros conceptos ${ }^{9}$. Añade Suárez que a nuestra razón natural le toca juzgar en virtud de primeros principios evidentes que no podemos ignorar, aunque sí estamos en capacidad de ignorar otros principios particulares que se deriven de estos mismos; por ello, es a causa de este ejercicio de juzgar que Suárez advierte que es posible errar al respecto, aunque no sin culpa si se ignoran por mucho tiempo, ya que se pueden llegar a conocer con diligencia ${ }^{10}$. El hombre debe velar porque sus acciones acontezcan conforme a la voluntad de Dios y evitar los errores que pudiera derivar. Por eso Larrainzar propone que "Suárez contempla la criatura en concreto y singularizada en cuanto su movimiento efectivo lleva una dialéctica entre la acción real y la querida por su Creador" (1977, 175). Con esto Wittgenstein estaría de acuerdo, pues la filosofía no es sino la clarificación lógica de los pensamientos, no es una doctrina sino una actividad, y su fin esencial no es sino la aclaración de proposiciones (TLP 4.III). Dando por terminado este examen, observamos así que para ambos filósofos la metodología ejercida en el ámbito jurídico o moral nos sugiere una revisión de nuestros conceptos y, por tanto, preceptos. Es patente que lo jurídico como la filosofía es una

9 Ya Suárez nos advierte en las Disputaciones Metafísicas acerca de cuidar de nuestros conceptos para no transferir a las cosas nuestro modo de concebir y juzgarlas inapropiadamente $(1960,410)$.

I0 Hay que decir, no obstante, que Suárez concibe al decálogo y leyes semejantes como aquellas que no se pueden ignorar sin culpa con el tiempo. Sin embargo, dejo esta afirmación a considerar a juicio del lector como relevante, en la medida que sabemos que podemos tomar lo esencial del decálogo: el amor a Dios sobre todas las cosas y al prójimo como a uno mismo. Con lo que la metodología jurídica de Suárez podría ser utilizada mejor por nuestra reflexión en cuanto expuesta de esa manera no entraría en conflicto tampoco con la esencia de lo jurídico que se aceptó alguna vez. 
búsqueda de la claridad en relación con la ley. No es algo que se dice sino se muestra, pero que se mostrará cumplidamente en el decir en tanto existan personas con inteligencia y, sobre todo, corazón.

\section{Bibliografía}

Baciero, Francisco, 2007. La ley moral natural según Francisco Suárez. Revista Española de Filosofía Medieval 14, 105-1 18. https://doi.org//0.21071/refime.v14i.6242Fann, K. T., 2003. El concepto de filosofía en Wittgenstein. Madrid: Editorial Tecnos. https://doi. org/l0.2107I/refime.v14i.6242

Hartnack, Justus, 1972. Wittgenstein y la filosofía contemporánea. Barcelona: Ediciones Ariel.

Iturrioz, Jesús, 1949. Estudios sobre la metafísica de Francisco Suárez, S. I. Madrid: Estudios Onienses.

Mounce, H. O., 2007. Introducción al Tractatus de Wittgenstein. Madrid: Editorial Tecnos.

Pole, David, 1966. Las filosofías de Ludwig Wittgenstein. Barcelona: Ediciones oikos-tau.

Suárez, Francisco, 1960. Disputaciones Metafísicas. Madrid: Editorial Gredos.

- 1967. Tratado de las leyes y de Dios legislador. Madrid: Instituto de estudios políticos.

Van Peursen, Cornelis Anthonie, 1973. Ludwig Wittgenstein, Introducción a su filosofía. Buenos Aires-México: Ediciones Carlos Lohle.

Wittgenstein, Ludwig, 1990. Conferencia sobre ética. Barcelona-Buenos Aires-México: Ediciones Paidós.

— 2009. Tractatus lógico-philosophicus. Madrid: Alianza Editorial.

- 2010. Investigaciones Filosóficas. Barcelona: Editorial Crítica. 